\title{
Steady State Levels of Pro-Dynorphin- Related End Products in the Striatum and Substantia Nigra of the Adult Rhesus Monkey
}

\author{
ROBERT M. DORES' AND HUDA AKIL \\ University of Michigan, Mental Health Research Institute, Ann Arbor, MI 48109
}

\begin{abstract}
DORES, R. M. AND H. AKIL. Steady state levels of pro-dynorphin-related end products in the striatum and substantia nigra of the adult rhesus monkey. PEPTIDES 6: Suppl. 2, 143-148, 1985.-Analysis of an acid extract of the striatum of the rhesus monkey revealed that the molar ratio of dynorphin $A(1-8)$-sized material and dynorphin ( $A(1-17)$-sized material is approximately $1: 1$. In addition, the molar ratios of the dynorphin A-related end products to both dynorphin B(1-13)-sized material and alpha-neo-endorphin-sized material were approximately 1:1. Fractionation of an acid extract of the substantia nigra by gel filtration and reverse phase HPLC revealed the following molar ratios for pro-dynorphin-related end products. The molar ratio of dynorphin $\mathrm{A}(1-8)$ to dynorphin $\mathrm{A}(1-17)$ is approximately 6:1. The molar ratios of dynorphin A-related end products to dynorphin $\mathrm{B}(1-13)$ and alpha-neo-endorphin were approximately 0.5 and 0.8 , respectively. Comparisons between proteolytic processing patterns of pro-dynorphin in the striatum and the substantia nigra of the rhesus monkey are considered. In addition, comparisons between pro-dynorphin processing in the substantia nigra of the rhesus monkey and the substantia nigra of the rat [4] are discussed.
\end{abstract}

Pro-dynorphin Striatum Substantia nigra Processing

SEQUENCES of the opioid peptides, alpha-neo-endorphin [11], dynorphin $A(1-17)$ [7], and dynorphin $B(1-13)[5,14]$ are all contained within the sequence of the polyprotein, prodynorphin [10]. Differential proteolytic processing of this precursor at sites of either paired basic amino acids (i.e., Lys-Arg) or at a single Arg residue can give rise to a variety of opioid end products. In addition to the peptides listed above, the following opioid peptides have also been detected in pro-dynorphin systems: beta-neo-endorphin [18], dynorphin $A(1-8)[17,24]$ and leumorphin $([19,35]$; the $\mathrm{COOH}-$ terminal extended form of dynorphin $B(1-13)$ ).

Several anatomical studies on the distribution of prodynorphin-related end products in the brain of the rat indicate that there is not just a single pro-dynorphin circuit in the central nervous system, but rather several independent prodynorphin networks which are distributed widely throughout the brain $[12,16,26,27,28,29,30,31]$. Accordingly, studies on the steady state levels of pro-dynorphin-related end products in the central nervous system of the rat $[2,25,32]$ indicate that pro-dynorphin can undergo differential posttranslational processing to yield distinct sets of end products in different regions of the rat brain. However, because of the complex anatomical distribution of pro-dynorphin perikarya and terminals in the central nervous system, it is necessary to go beyond regional analysis and focus on anatomically well defined pro-dynorphin networks. This study will con- sider processing of pro-dynorphin in the striato-nigral pathway.

Anatomical studies on the brain of the rat have clearly established that pro-dynorphin perikarya can be localized in the caudate-putamen (i.e., striatum; $[12,29,30]$ ). Independently, two groups have demonstrated by chemical lesion [26] and surgical lesion [34] experiments that pro-dynorphin perikarya located in the striatum project to the substantia nigra. A comparison of the steady state levels of dynorphin A-related material in the substantia nigra and the posterior pituitary, the terminal field for magnocellular neurons originating in the supraoptic and paraventricular nuclei [27, 28,31 ], revealed that the molar ratio of dynorphin $A(1-8)$ to dynorphin $A(1-17)$ in the posterior pituitary is approximately $1: 1$, whereas the molar ratio of these peptides in the substantia nigra is approximately $16: 1$ [4]. Thus, the proteolytic processing events that occur in the rat striato-nigral pathway result in the conversion of dynorphin $A(1-17)$, a highly selective kappa agonist, to dynorphin $A(1-8)$, an opioid with mixed selectively for kappa and delta receptors $[1,3,20,22$, $23,33]$. Since pro-dynorphin is differentially processed in two anatomically distinct systems within the rat brain, the present study was done to determine whether similar processing patterns for pro-dynorphin could be observed in the substantia nigra of a primate, the rhesus monkey.

${ }^{\prime}$ Send reprint requests to R. M. Dores, University of Denver, Department of Biological Sciences, Denver, CO 80208. 


\section{METHOD}

For these experiments the striatum (wet weight: $4.8 \mathrm{~g}$ ) and the substantia nigra (wet weight: $0.6 \mathrm{~g}$ ) were collected from an adult postmenopausal female rhesus monkey (species: Macaque mulatta), obtained from the Primate Research Center at the University of Michigan School of Medicine. The tissues were separately extracted in ten volumes of acetone: $0.1 \mathrm{~N} \mathrm{HCl} \mathrm{(3:1).} \mathrm{The} \mathrm{homogenate} \mathrm{was} \mathrm{cen-}$ trifuged for $45 \mathrm{~min}$ at $12,000 \mathrm{rpm}$, and the supernatant was concentrated under vacuum (Savant Speed Vac). The dried extract was dissolved in a volume of $10 \%$ formic acid and fractionated by gel filtration on a Sephadex G-50 superfine column (Pharmacia) equilibrated in $10 \%$ formic acid which contained $100 \mu \mathrm{g} / \mathrm{ml}$ bovine serum albumin. Following gel filtration, aliquots of the column fractions were concentrated under vacuum and analyzed by radioimmunoassay. The recovery of immunoreactivity following gel filtration averaged $85 \%$.

Radioimmunoassays for dynorphin A(1-17), dynorphin $A(1-8)$, dynorphin $B(1-13)$, and alpha-neo-endorphin were done following the method described by Ghazarossian et al. [6] with some modifications. All primary antisera were raised in rabbits as described by Khachaturian et al. [12]. Synthetic dynorphin $A(1-17)$, dynorphin $A(1-8)$, and alpha-neoendorphin were purchased from Bachem (Torrance, CA). Synthetic dynorphin B(1-13) was provided by Dr. Richard Houghton (Scripps Institute). Peptides were iodinated by the chloramine $T$ procedure. For dynorphin $A(1-17)$ and dynorphin $A(1-8)$ assays the RIA buffer consisted of methanol/0.1 $\mathrm{N} \mathrm{HCl}(3: 1)$ and $150 \mathrm{mM}$ sodium phosphate, $0.1 \%$ bovine serum albumin, $0.1 \%$ triton $\mathrm{X}-100, \mathrm{pH} 8.2$ buffer in a ratio of 1:2.5. For dynorphin $B(1-13)$ and alpha-neo-endorphin assays, the RIA buffer consisted of methanol/0.1 N HCl (3:1) and $150 \mathrm{mM}$ sodium phosphate, $1 \%$ bovine serum albumin, $0.1 \%$ triton $\mathrm{X}-100, \mathrm{pH} 7.5$ buffer, in a ratio of $1: 2.5$. For all RIAs, the final reaction volume was $200 \mu \mathrm{l}$. RIAs were run at $4^{\circ} \mathrm{C}$ for $18-24 \mathrm{hr}$ and terminated by the double antibody procedure using goat anti-rabbit IgG. The primary antisera used in these assays had the following specificities.

\section{Dynorphin A(1-17)}

Antisera No. 54 (final concentration: 1:12,000) was raised against synthetic dynorphin $\mathrm{A}(1-17)$. This antisera has $80 \%$ molar crossreactivity with dynorphin $\mathrm{A}(1-13)$, but less than $0.1 \%$ molar crossreactivity with dynorphin $A(1-8)$, dynorphin $B(1-13)$, alpha-neo-endorphin and leucine enkephalin. This antisera crossreacts in a parallel manner with $11 \mathrm{~K}, 6 \mathrm{~K}$, and $4 \mathrm{~K}$ forms of dynorphin A-related immunoreactivity [4]. The midpoint of this assay is $70 \mathrm{fmol} /$ tube.

\section{Dynorphin A(1-8)}

Antisera No. 73 (final concentration: 1:5,000) was raised against synthetic dynorphin $\mathrm{A}(1-8)$. This antisera has $1 \%$ molar crossreactivity with dynorphin $A(1-17)$ and less than $0.1 \%$ molar crossreactivity with alpha-neo-endorphin, dynorphin $B(1-13)$ and leucine enkephalin. This antisera does not appear to crossreact with high molecular weight forms of dynorphin A. The midpoint of this assay is 90 fmol/tube.

\section{Dynorphin B(1-13)}

Antisera No. 94 (final concentration: 1:4,000) was raised against synthetic dynorphin $\mathrm{B}(1-13)$. This antisera has less
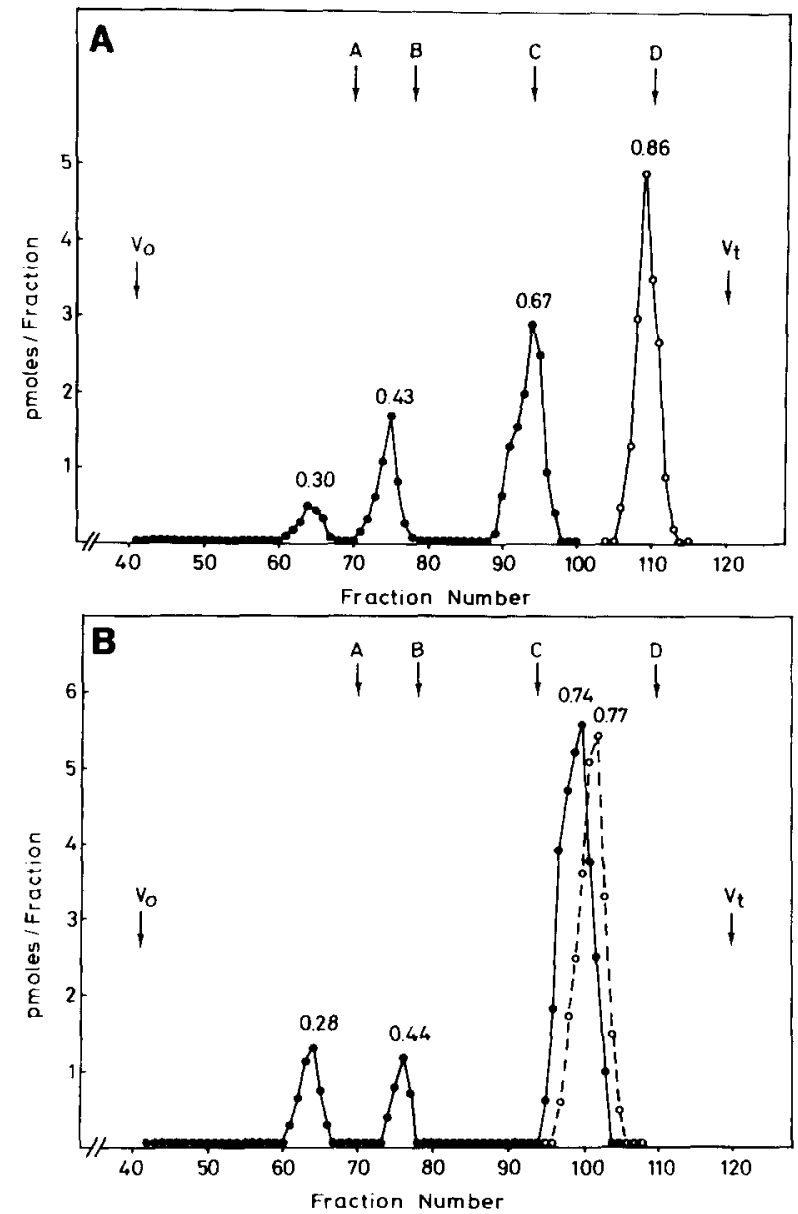

FIG. 1. Gel filtration of an acid extract of the striatum of the rhesus monkey. An acid extract of 0.5 equivalents of striatum (wet weight: $2.6 \mathrm{~g})$ was fractionated by gel filtration on a Sephadex G-50 superfine column $(1.5 \times 70 \mathrm{~cm})$ equilibrated in $10 \%$ formic acid $/ 0.1 \%$ bovine serum albumin. The flow rat was $1.5 \mathrm{ml} / \mathrm{hr}$ and $1 \mathrm{ml}$ fractions were collected. The $V_{11}$ was marked with bovine serum albumin and the $\mathrm{V}_{\mathrm{t}}$ was marked with 2,mercaptoethanol both detected spectrophotometrically at $\mathrm{A}_{2 x_{0}}$. Aliquots of fractions were concentrated and analyzed by radioimmunoassay. (A) Profile of dynorphin A(117)-related immunoreactivity (-) and dynorphin A(1-8)-related immunoreactivity $(O-O)$. (B) Profile of dynorphin B-related immunoreactivity (-) and alpha-neo-endorphin-related immunoreactivity $(\mathrm{O}-\mathrm{O})$. The following standards were used to calibrate this column: (1) synthetic ACTH(1-39); (2) synthetic human beta-endorphin(1-31); (3) synthetic porcine dynorphin $A(1-17)$; (4) synthetic porcine dynorphin A(1-8).

than $0.1 \%$ molar crossreactivity with dynorphin $A(1-17)$, dynorphin $A(1-8)$, alpha-neo-endorphin or leucine enkephalin. However, this antisera does crossreact in a parallel manner with $6 \mathrm{~K}$ and $4 \mathrm{~K}$ forms of dynorphin B-related material. The midpoint of this assay is $60 \mathrm{fmol} / \mathrm{tube}$.

\section{Alpha-Neo-Endorphin}

Antisera No. 59 (final concentration: 1:4,000) was raised against synthetic alpha-neo-endorphin. This antisera has $1 \%$ molar crossreactivity with beta-neo-endorphin, and less than $0.1 \%$ molar crossreactivity with dynorphin $\mathrm{A}(1-17)$, dynorphin $A(1-8)$, alpha-neo-endorphin or leucine enkephalin. 
TABLE 1

\begin{tabular}{lc}
\hline Peptide & pmol/g Tissue \\
\hline \multicolumn{1}{c}{ Striatum } \\
Dynorphin A (1-17) & \\
Dynorphin A (1-8) & 10 \\
Dynorphin B (1-13) & 12 \\
Alpha-neo-endorphin & 21 \\
\multicolumn{1}{c}{ Substantia Nigra } & 18 \\
& \\
Dynorphin A (1-17) & 12 \\
Dynorphin A (1-8) & 74 \\
Dynorphin B (1-13) & 45 \\
Alpha-neo-endorphin & 69 \\
\hline
\end{tabular}

This antisera does not appear to crossreact with any high molecular weight forms of alpha-neo-endorphin-related material. The midpoint of this assay is $70 \mathrm{fmol} / \mathrm{tube}$.

Peaks of immunoreactivity isolated by gel filtration were separately analyzed by reverse phase high performance liquid chromatography (HPLC) on a Beckman ODS ultrasphere 5 micron column $(4.6 \mathrm{~mm} \times 25 \mathrm{~cm})$. The column was eluted with a 4 to $32 \%$ nonlinear gradient of acetonitrile in $0.1 \%$ trifluoacetic acid (Pierce). The recovery of immunoreactivity from this column averaged $80 \%$.

\section{RESULTS}

Steady State Levels of Pro-Dynorphin-Related Products in the Striatum

Anatomical and biochemical analyses of the striato-nigral pro-dynorphin network have primarily focused on the rat system $[4,12,26,34]$. Anatomical studies of the rhesus monkey central nervous system indicate that pro-dynorphin perikarya can also be demonstrated in the caudate nucleus of this species [13]. In addition, pro-dynorphin-related immunoreactivity is primarily concentrated in the zona reticulata of the substantia nigra of this species with a distribution similar to what has already been reported for the rat substantia nigra [12]. The apparent similarities between the well defined striato-nigral pro-dynorphin pathway in the rat and the apparent striato-nigral pathway in the rhesus monkey prompted us to compare the steady state levels of prodynorphin products in the striatum (caudate and putamen) and substantia nigra of the rhesus monkey. Furthermore, additional studies on the processing of pro-dynorphin in the brain of a primate are of interest, given the observation that the concentration of pro-dynorphin-related products in the human substantia nigra is particularly high relative to other regions of the brain [15].

Analysis of an extract of the striatum of the rhesus monkey by gel filtration chromatography in conjunction with radioimmunoassay analyses is shown in Fig. 1. Four peaks of dynorphin A-related material were detected in this extract (Fig. 1A). The dynorphin A(1-17) RIA detected two minor peaks $\left(K_{a t}=0.30\right.$ and 0.43 , respectively) and one major peak $\left(\mathrm{K}_{\mathrm{at}}=0.67\right)$. The minor peaks have apparent molecular weights of approximately $6 \mathrm{~K}$ and $4 \mathrm{~K}$, respectively, and are similar to peaks of immunoreactivity detected with this RIA
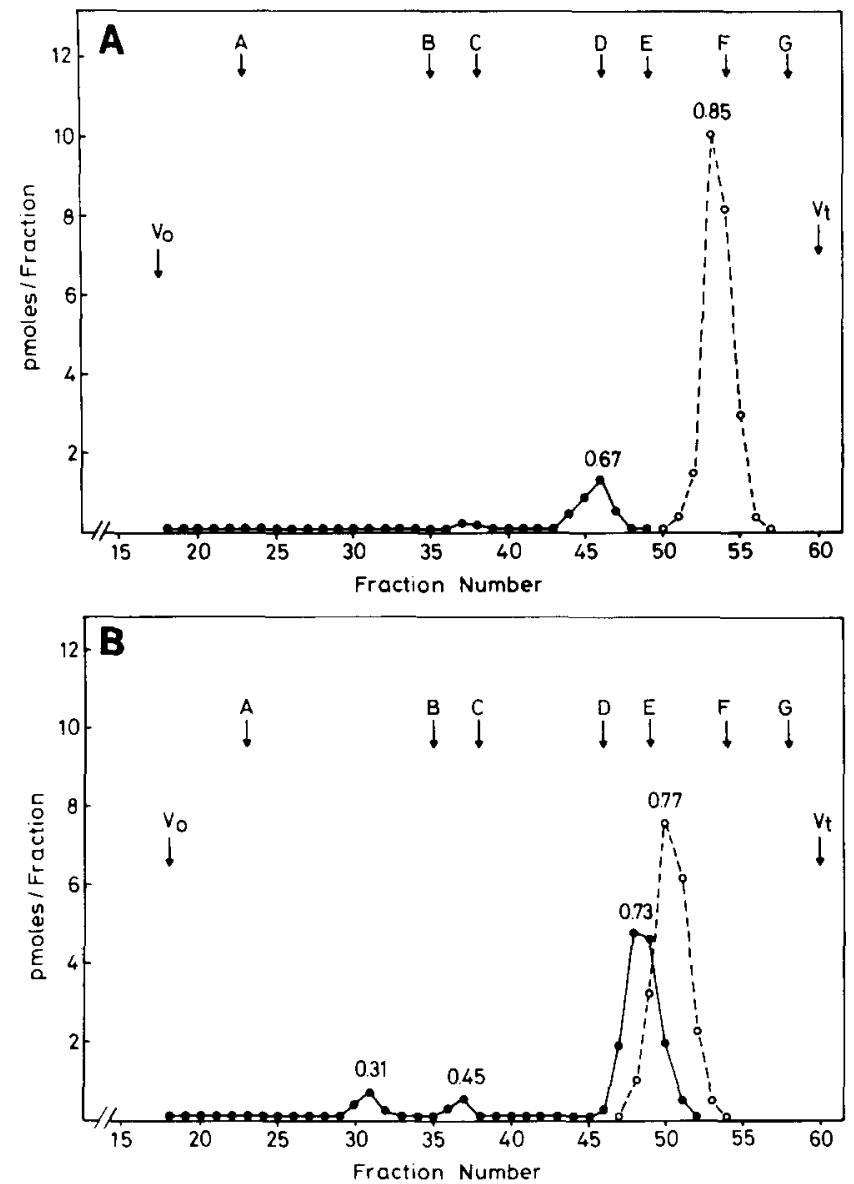

FIG. 2. Gel filtration of an acid extract of the substantia nigra of the rhesus monkey. An acid extract of 0.5 equivalents of substantia nigra (wet weight: $0.3 \mathrm{~g}$ ) was fractionated by gel filtration on a Sephadex G-50 superfine column $(1 \times 50 \mathrm{~cm})$ equilibrated in $10 \%$ formic acid $/ 0.1 \%$ bovine serum albumin as described in the legend to Fig. 1. The fraction size was $0.4 \mathrm{ml}$. (A) Profile of dynorphin A(117)-related immunoreactivity (- ) and dynorphin (A(1-8)-related immunoreactivity $(O-O)$. (B) Profile of dynorphin B-related immunoreactivity (-๑) and alpha-neo-endorphin-related immunoreactivity $(O-O)$. The standards used to calibrate this column were: (A) cytochrome C; (B) synthetic porcine ACTH(1-39); (C)) synthetic human beta-endorphin(1-31); (D) synthetic porcine dynorphin $A(1-17)$; (E) synthetic porcine dynorphin $B(1-13)$; (F) synthetic porcine dynorphin $A(1-8) ;(G)$ synthetic leucine enkephalin.

from extracts of rat posterior pituitary [4]. The major peak of dynorphin A(1-17)-related immunoreactivity eluted at the same position as synthetic porcine dynorphin $\mathrm{A}(1-17)$. The dynorphin A(1-8) RIA detected a single peak of immunoreactivity $\left(\mathrm{K}_{\mathrm{ar}}=0.86\right)$ with the same apparent molecular weight as synthetic porcine dynorphin $\mathrm{A}(1-8)$. In this tissue the molar ratio of dynorphin $A(1-8)$-sized material to dynorphin $A(1-17)$ is approximately $1: 1$ (Table 1$)$. These results are in contrast to analyses of the rat striatum where the levels of dynorphin $A(1-8)$-sized material range from 9 to 16 fold higher than the dynorphin $A(1-17)$-sized material ([25,32]; Dores, unpublished data).

The dynorphin B(1-13) RIA also detected multiple peaks of immunoreactivity (Fig. 1B). Two minor peaks of immunoreactivity $\left(\mathrm{K}_{\mathrm{ar}}=0.28\right.$ and 0.44$)$ correspond to material 
with apparent molecular weights of $6 \mathrm{~K}$ and $4 \mathrm{~K}$, respectively. The major peak of immunoreactivity $\left(K_{a v}=0.74\right)$ has the same apparent molecular weight as synthetic porcine dynorphin $B(1-13)$. In this tissue the molar ratio of dynorphin $\mathrm{B}(1-13)$-sized material to dynorphin A (dynorphin A(1-8)- + dynorphin $A(1-17)$-sized material) is approximately $1: 1$. The alpha-neo-endorphin RIA detected a single peak of immunoreactivity $\left(K_{a v}=0.77\right)$ and this peak has the same apparent molecular weight as synthetic porcine alpha-neoendorphin (Fig. 1B). The alpha-neo-endorphin-sized material is also present in roughly equimolar amounts with the dynorphin A-related material (Table 1).

Steady State Levels of Pro-Dynorphin-Related End Products in the Substantia Nigra

The preceding section dealt with a consideration of the pro-dynorphin-related products in the striatum (Fig. 1 and Table 1). Although the striatum contains pro-dynorphin perikarya which are presumed to project to the substantia nigra, it is clear from anatomical studies on both the rat [12] and rhesus monkey [13] striatum that this region of the brain not only contains perikarya, but also contains fibers of passage as well as local terminal fields. By contrast, the substantia nigra is devoid of pro-dynorphin perikarya and con'ains only terminal fields, thus the forms of pro-dynorphinlated end products detected in this area represent the final icessed forms which are presumably being stored for secretion.

Analysis of an extract of the substantia nigra of the rhesus monkey are presented in Figs. 2 and 3 and Table 1 . Gel filtration of this extract (Fig. 2A) followed by analysis with the dynorphin $A(1-17)$ RIA detected two minor peaks of dynorphin A-related immunoreactivity $\left(\mathrm{K}_{\mathrm{av}}=0.45\right.$ and 0.67$)$. The former peak eluted with an apparent molecular weight of $4 \mathrm{~K}$ and the latter peak has the same apparent molecular weight as synthetic porcine dynorphin $A(1-17)$. The major peak of dynorphin A-related material in this extract was detected with the dynorphin A(1-8) RIA. This peak of immunoreactivity $\left(K_{a v}=0.85\right)$ has the same apparent molecular weight as synthetic dynorphin $A(1-8)$. The identities of the dynorphin $A(1-17)$-sized material and the dynorphin $A(1-$ 8 )-sized material isolated in Fig. $2 \mathrm{~A}$ were confirmed by reverse phase HPLC analysis (Fig. 3B). The molar ratios of these dynorphin A-related end products are summarized in Table 1. In the rhesus monkey substantia nigra the molar ratio of dynorphin $A(1-8)$ to dynorphin $A(1-17)$ is approximately $6: 1$.

Analysis of the extract of the substantia nigra with the dynorphin $B(1-13)$ RIA also revealed multiple peaks of immunoreactivity (Fig. 2B). Two minor peaks $\left(\mathrm{K}_{\mathrm{av}}=0.31\right.$ and $0.45)$ and a major peak $\left(\mathrm{K}_{\mathrm{av}}=0.73\right)$ were detected. The latter peak has the same apparent molecular weight as synthetic dynorphin $B(1-13)$. Analysis of this peak of immunoreactivity by reverse phase HPLC (Fig. 3A) indicated that the dynorphin $\mathrm{B}(1-13)$-sized material migrated with the same retention time as synthetic porcine dynorphin $B(1-13)$. The molar ratio of dynorphin $B(1-13)$ to dynorphin $\mathrm{A}($ dynorphin $\mathrm{A}(1-17)+$ dynorphin $\mathrm{A}(1-8))$ is approximate 0.5:1 (Table 1).

Analysis of the extract of the substantia nigra with the alpha-neo-endorphin RIA (Fig. 2B) revealed a single peak of immunoreactive material $\left(K_{a v}=0.77\right)$ with the same apparent molecular weight as synthetic porcine alpha-neo-endorphin. The identity of this peak was confirmed by reverse phase
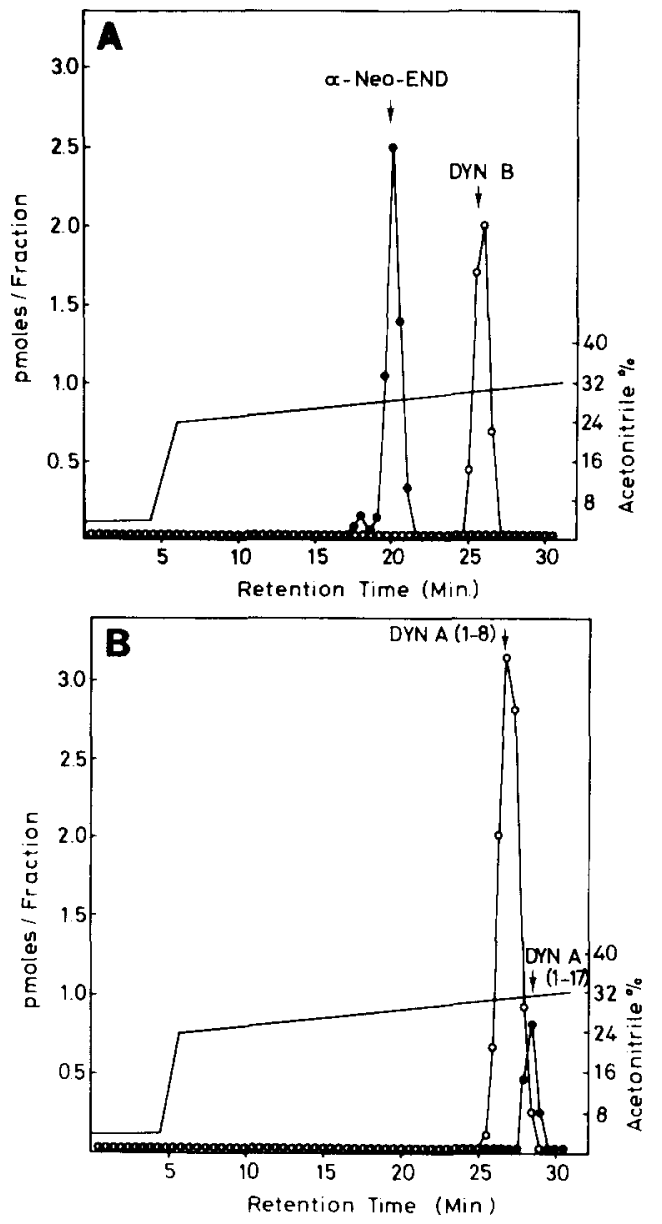

FIG. 3. HPLC profiles of dynorphin A(1-17), dynorphin A(1-8), dynorphin $B(1-13)$ and alpha-neo-endorphin isolated from the substantia nigra of the rhesus monkey. Reverse phase HPLC analysis of purified pro-dynorphin-related end products was done on a Beckman ODS ultrasphere 5 micron column as described in the Method section. (A) Aliquots $(0.25 \mathrm{ml})$ of fractions No. 47-53 from Fig. 2 were pooled and concentrated. The concentrate was redissolved in $0.08 \mathrm{ml}$ of $0.1 \%$ trifluoacetic acid and applied to the column. The fraction size was $1 \mathrm{ml}$ and $0.5 \mathrm{ml}$ aliquots were analyzed with both the dynorphin B(1-13) RIA and the alpha-neo-endorphin RIA. (B) Aliquots $(0.3 \mathrm{ml})$ from fractions No. 52-55 from Fig. 2 were pooled and concentrated for HPLC analysis. The fraction size was 1 $\mathrm{ml}$ and $0.5 \mathrm{ml}$ aliquots were analyzed with the dynorphin $\mathrm{A}(1-8)$ RIA. In a separate chromatogram, aliquots $(0.25 \mathrm{ml})$ of fractions No. 44-47 from Fig. 2 were pooled and concentrated for HPLC analysis. The fraction size was $1 \mathrm{ml}$ and $0.5 \mathrm{ml}$ aliquots were analyzed with the dynorphin A(1-17) RIA. For convenience, the dynorphin A(1-8) and the dynorphin $A(1-17)$ chromatograms were drawn together. The following synthetic standards were run separately and the retention times are marked with an arrow: alpha-neo-endorphin, dynorphin $B(1-13)$, dynorphin $A(1-8)$ and dynorphin $A(1-17)$.

HPLC analysis (Fig. 3A). The molar ratio of alpha-neoendorphin to dynorphin $A$ in this tissue is approximately 0.8:1.

\section{DISCUSSION}

The action of opiates on the nigro-striatal dopaminergic pathway is a very complex issue (for review see [21]). A recent study indicates that administration of opioid peptides 
at the level of the zona reticulata of the substantia nigra appears to influence the activity of the dopaminergic perikarya in the zona compacta of the substantia nigra [8]. Accordingly, anatomical studies of the zona reticulata of the rat and rhesus monkey brain $[12,13]$ indicate that this region of the substantia nigra contains an extensive pro-dynorphin terminal field. Lesion studies have established that in the rat brain pro-dynorphin perikarya originating in the striatum project to the substantia nigra [26,34]. Although it appears that the major pro-dynorphin projection to the substantia nigra comes from the striatum, the possibility of extrastriatal projections can not be eliminated at this time. With the detection of pro-dynorphin perikarya in the striatum of the rhesus monkey and the extensive pro-dynorphin terminal field in the substantia nigra of this species, it appears highly likely that a pro-dynorphin striato-nigral network is also present in the rhesus monkey.

In the present study we examined the steady state levels of pro-dynorphin-related products in the striatum and substantia nigra of the rhesus monkey. Both regions of the rhesus monkey brain contain dynorphin $A(1-17)-$, dynorphin A(1-8)-, dynorphin B(1-13)-, and alpha-neo-endorphin-sized material which appear to be chromatographically identical to the porcine forms of these pro-dynorphin opioid end products. Sequence analysis of the pro-dynorphin gene obtained from a human genomic DNA library [9] indicates that in this primate the opioid peptide sequences are identical to the porcine sequences [10]. Thus in mammals as diverse as rodent, porcine and primate the opioid sequences of prodynorphin are highly conserved.

In the striatum of the rhesus monkey roughly equimolar amounts of dynorphin $A$ (dynorphin $A(1-17)+$ dynorphin $\mathrm{A}(1-8))$, dynorphin $\mathrm{B}(1-13)$, and alpha-neo-endorphin were detected. One of the striking features of the rhesus monkey striatum is the roughly equimolar amounts of dynorphin $A(1-17)$ - and dynorphin A(1-8)-sized material. This is in contrast to the striatum of the rat where the predominant form of dynorphin $\mathrm{A}$ is dynorphin $\mathrm{A}(1-8)[25,32]$. Furthermore, although high molecular weight forms of dynorphin A-related material and dynorphin B-related material were detected, the predominant forms of pro-dynorphin products in the striatum were the low molecular opioid peptides.

In the substantia nigra of the rhesus monkey proteolytic processing of pro-dynorphin has proceeded even further than in the striatum. Although high molecular weight forms of dynorphin A-related and dynorphin B-related material were detected in the substantia nigra, these forms were present in a lower percentage than in the striatum. These data suggest that proteolytic processing proceeds to near completion in the substantia nigra. Further evidence of the extent of proteolytic processing in the substantia nigra is seen in the molar ratio of dynorphin $A(1-17)$ and dynorphin $A(1-8)$. In the striatum these forms were present in roughtly a $1: 1$ ratio, whereas in the substantia nigra there is 6 fold more dynorphin $A(1-8)$ as compared to dynorphin $A(1-17)$. The increase in the levels of dynorphin $A(1-8)$ in the substantia nigra as compared to the striatum and the accompanying shift in opiate receptor specificity of dynorphin $A(1-8)$ may have functional significance. It is noteworthy, however, that the ratio of the forms of dynorphin $A$ in the rhesus monkey substantia nigra is not as extreme as the ratio of these forms in the rat substantia nigra, where there is approximately 16 fold more dynorphin $\mathrm{A}(1-8)$ as compared to dynorphin $\mathrm{A}(1-$ 17) $[4]$.

Another difference between the steady state levels of pro-dynorphin products in the striatum and substantia nigra of the rhesus monkey is that the molar ratio of dynorphin $A$, dynorphin $B(1-13)$, and alpha-neo-endorphin were approximately $1: 1$ in the striatum, however, in the substantia nigra there were approximately $20 \%$ and $50 \%$ less of alpha-neoendorphin and dynorphin $\mathrm{B}(1-13)$, respectively, as compared to dynorphin $A$ end products. The minor drop in alpha-neo-endorphin may indicate a conversion to betaneo-endorphin. The $50 \%$ drop in dynorphin $\mathrm{B}(1-13)$ relative to dynorphin $A$ end products may reflect a conversion of the former to leucine enkephalin. The use of a biosynthetic labelling paradigm will be required in order to properly evaluate these possibilities.

Finally, the results reported in this study reflect the steady state levels of pro-dynorphin products in the adult female rhesus monkey. Further studies are needed on animals of both sexes at different periods in ontogeny in order to obtain a better understanding of pro-dynorphin processing in primates.

\section{ACKNOWLEDGEMENTS}

We wish to thank Dr. Richard Houghton for providing synthetic dynorphin B(1-13) and Dr. Stanley J. Watson and Ms. Monika Knobloch for their assistance during the dissection of the rhesus monkey brain. We are grateful to Mr. Guilio Baldrighi for drawing the figures and Ms. Patty Moore for preparation of the manuscript. This work was supported by NIDA Center grant DA00154, NIDA grant DA02265, NIMH grant NH 39717 and the Theophile Raphael Grant from the University of Michigan.

\section{REFERENCES}

1. Chavkin, C. and A. Goldstein. Specific receptor for the opioid peptide dynorphin: structure-activity relationships. Proc Natl Acad Sci USA 78: 6543-6547, 1981

2. Cone, R. I., E. Weber, J. D. Barchas and A. Goldstein. Regional distribution of dynorphin and neo-endorphin peptides in rat brain, spinal cord, and pituitary. $J$ Neurosci 3: 2146-2152, 1983.

3. Corbett, A. D., S. J. Paterson, A. T. McKnight, J. Magnan and H. Kosterlitz. Dynorphin(1-8) and dynorphin(1-9) are ligands for the kappa subtype of opiate receptor. Nature 299: 79-81, 1982.

4. Dores, R. M., M. E. Lewis, H. Khachaturian, S. J. Watson and H. Akil. Analysis of opioid and non-opioid end products of pro-dynorphin in the substantia nigra of the rat. Neuropeptides, 5: 501-504, 1985.
5. Fischli, W., A. Goldstein, M. W. Hunkapiller and L. E. Hood Isolation and amino acid sequence analysis of a 4,000-dalton dynorphin from porcine pituitary. Proc Natl Acad Sci USA 79: $5435-5437,1982$.

6. Ghazarossian, V. E., C. Chavkin and A. Goldstein. A specific radioimmunoassay for the novel opioid peptide dynorphin. Life Sci 27: 75-86, 1980 .

7. Goldstein, A., W. Fischli, L. I. Lowney, M. Hunkapiller and L. Hood. Porcine pituitary dynorphin: complete amino acid sequence of the biologically active heptadecapaptide. Proc Natl Acad Sci USA 78: 7219-7223, 1981.

8. Hommer, D. W. and A. Pert. The action of opiates in the rat substantia nigra: An electrophysiological analysis. Peptides 4: 603-608, 1983. 
9. Horikawa, A., T. Takai, M. Toyosato, H. Takahashi, M. Noda H. Kakidani, T. Kubo, T. Hirose, S. Inayama, H. Hayashida T. Miyata and $S$. Numa. Isolation and structural organization of the human preproenkephalin B gene. Nature 306: 611-614, 1983.

10. Kakidani, H., Y. Furutani, H. Takahashi, M. Noda, Y. Morimoto, T. Hirose, M. Asai, S. Inayama, S. Nakanishi and S Numa. Cloning and sequence analysis of cDNA for porcine beta-neo-endorphin/dynorphin precursor. Nature 298: 245-249, 1982.

11. Kangawa, K., N. Minamino, N. Chino, S. Sakakibara and H. Matsuo. The complete amino acid sequence of alpha-neoendorphin. Biochem Biophys Res Commun 99: 871-878, 1981.

12. Khachaturian, H., S. J. Watson, M. E. Lewis, D. Coy, A Goldstein and A. Akil. Dynorphin immunocytochemistry in the rat central nervous system. Peptides 3: 941-954, 1982.

13. Khachaturian, H., M. E. Lewis, S. Haber, H. Akil and S. J. Watson. Prodynorphin peptide immunocytochemistry in the rhesus monkey brain. Peptides 6: Suppl 2, 155-166, 1985.

14. Kilpatrick, D. L., H. W. Wahlstrom, H. W. Lahm, R. Blacher and $S$. Udenfriend. Rimorphin, a unique, naturally occurring [leu]enkephalin-containing peptide found in association with dynorphin and alpha-neo-endorphin. Proc Natl Acad Sci USA 79: 6480-6483, 1982.

15. Maysinger, D., V. Hollt, B. R. Seizinger, P. Mehraein, A. Pasi and A. Herz. Parallel distribution of immunoreactive alphaneo-endoprhin and dynorphin in rat and human tissue. Neuropeptides 2: 211-225, 1981.

16. McGinty, J. F., D. Van der Kooy and F. E. Bloom. The distribution and morphology of opioid peptide immunoreactive neurons in the cerebral cortex of rats. $J$ Neurosci 4: 1104-1117, 1984.

17. Minamino, N., K. Kangawa, A. Fukuda and H. Matsuo. A new opioid octapeptide related to dynorphin from porcine hypothalamus. Biochem Biophys Res Commun 95: 1475-1481, 1980.

18. Minamino, N., K. Kangawa, N. Chino, S. Sakakibara and H. Matsuo. Beta-neo-endorphin, a new hypothalamic "big" leuenkephalin of porcine origin: Its purification and the complete amino acid sequence. Biochem Biophys Res Commun 99: 864 $870,1981$.

19. Nakao, K., M. Suda, M. Sakamoto, T. Yoshimasa, N. Norii, Y. Ikeda, C. Yanaihara, N. Yanaihara, S. Numa and H. Imura. Leumorphin is a novel endogenous opioid peptide derived from preproenkephalin B. Biochem Biophys Res Commun 117: 695$701,1983$.

20. Oka, T., K. Negishi, M. Kajiwara, Y. Watanabe, Y. Ishizuka and T. Matsumiya. The choice of opiate receptor subtype by neo-endorphins. Eur J Pharmacol 79: 301-305, 1982.

21. Pert, A. Effects of opiates on nigrostriatal dopaminergic activity. In: Characteristics and Functions of Opioids, edited by J. van Ree and L. Terenius. New York: Elsevier/North-Holland Biomedical Press, 1978, pp. 389-401.
22. Quirion, R. and A. S. Weiss. Peptide E and other proenkephalin-derived peptides are potent kappa opiate receptor agonists. Peptides 4; 445-449, 1983.

23. Schulz, R., M. Wuster and A. Herz. Endogenous ligands for kappa-opiate receptors. Peptides 3: 973-976, 1982

24. Seizinger, B. R., V. Hollt and A. Herz. Evidence for the occurrence of the opioid octapeptide dynorphin-(1-8) in the neurointermediate pituitary of rats. Biochem Biophys Res Commun 103: 197-205, 1981.

25. Seizinger, B. R., C. Grimm, V. Hollt and A. Herz. Evidence for a selective processing of proenkephalin $\mathrm{B}$ into different opioid peptides forms in particular regions of rat brain and pituitary. $J$ Neurochem 42: 447-457, 1984.

26. Vincent, S., T. Hokfelt, I. Christensson and L. Terenius. Immunohistochemical evidence for a dynorphin immunoreactive striato-nigral pathway. Eur J Pharmacol 85: 251-252, 1982.

27. Watson, S. J., H. Akil, V. E. Ghazarossian and A. Goldstein Dynorphin immunocytochemical localization in brain and peripheral nervous system: Preliminary studies. Proc Natl Acad Sci USA 78: 1260-1263, 1981

28. Watson, S. J., H. Akil, W. Fischli, A. Goldstein, E. Zimmerman, G. Nilaver and T. B. van Wimersma Gredanus. Dynorphin and vasopressin: common localization in magnocellula neurons. Science 216: 85-87, 1982.

29. Watson, S. J., H. Khachaturian, D. Coy, L. Taylor and H. Akil Dynorphin is located throughout the CNS and is often colocalized with alpha-neo-endorphin. Life $S_{c i}$ 31: 1871-1873. 1982.

30. Watson, S. J., H. Khachaturian, L. Taylor, W. Fischli, A Goldstein and H. Akil. Prodynorphin peptides are found in the same neurons throughout rat brain: Immunocytochemical study. Proc Natl Acad Sci USA 80: 891-894, 1983.

31. Weber, E., K. A. Roth and J. D. Barchas. Colocalization of alpha-neo-endorphin and dynorphin immunoreactivity in hypothalamic neurons. Biochem Biophys Res Commun 103: 951-958, 1981

32. Weber, E., C. J. Evans and J. D. Barchas. Predominance of the amino-terminal octapeptide fragment of dynorphin in rat brain regions. Nature 299: 77-79, 1982.

33. Young, E., J. M. Walker, R. Houghton and H. Akil. ["H]dynorphin A binds selectively to guinea pig brain. Fiur.J Pharmacol 91: 327-328, 1983

34. Zamir, N., M. Palkovits, E. Weber, E. Mezey and M. J. Brownstein. A dynorphinergic pathway of leu-enkephalin production in rat substantia nigra. Nature 307: 643-645, 1984.

35. Zhu, Y. X., V. Hollt and H. Loh. Immunoreactive peptides related to dynorphin $\mathrm{B}$ (=rimorphin) in the rat brain. P(')tides 4 : 871-874, 1983. 